\title{
Formulation and Performance Evaluation of Calendula Officinalis Linn Extract Loaded Ethosomal Cream
}

\author{
Archana R. Dhole*, Khushabu M. Mulla, Sushmita S. Salunkhe, Komal S. Talekar, \\ Akshay R. Yadav, Dr. Chandrakant S. Magdum \\ Rajarambapu College of Pharmacy, Kasegaon, Sangli, Maharashtra-415404 \\ *Corresponding author mail: dholearchanarcp@gmail.com
}

\begin{abstract}
Among the various species of the genus Calendula, $C$. officinalis is the only one, which is extensively used clinically throughout the world. Pharmacological studies reveal that $\mathrm{C}$. officinalis exhibits antibacterial, antiviral, anti-inflammatory, anti-tumor and antioxidant properties, helps promote the healing of minor burns, scrapes and skin irritations and relieves sunburn and minor cuts. The objective of this study was to optimize conditions for encapsulating Calendula officinalis Linn extract. Thus a novel approach to effectively treat wrinkles, helps promote the healing of minor burns, scrapes and skin irritations and relieves sunburn and minor cuts by delivery of an antioxidant using a special lipid vesicular carrier, the Ethosomal cream was prepared.
\end{abstract}

Keywords: Ethosomes, C. officinalis, Lipid vesicular carrier, Characterization, Evaluation.

\section{INTRODUCTION}

C. officinalis has been included in number of herbal formulations, which are in clinical us e for the treatment of various ailments like central nervous system disorders ${ }^{1}$. Keeping in view the ethnopharmacology, phytochemical and pharmacological reports, low toxicity and frequency of use, $C$. officinalis seems to hold great potential for in depth investigation for various biological activities $^{2-4}$. It difficult to formulate in an acceptable, stable composition for cosmetic use. Ethosomes are noninvasive delivery carriers that enable drugs to reach the deep skin layers and/or the systemic circulation ${ }^{5-8}$. These are soft, malleable vesicles tailored for improved delivery of active agents. They are composed mainly of phospholipids, (phosphatidylcholine, phosphatidylserine, phosphatitidic acid), high concentration of ethanol and water. Since Calendula contents are hydrophobic, it is considered to be a good candidate for ethosomal 
incorporation, as it can be encapsulated in the lipid layer of the ethosomes ${ }^{9-12}$. These observations facilitate the doorway of novel delivery systems in the development of antiwrinkle creams etc. There is no such Ethosomal cream formulation available in market which shows better efficacy. Considering the fact, that to treat wrinkles antioxidant has to reach to the level of dermis; Calendula officinalis Linn extract ethosomal application of on the skin can offer the advantage of delivering the antioxidant directly to the site and produce prompt effects. Ethosomal carriers are systems containing soft vesicles ${ }^{13-15}$. They are composed mainly of phospholipid (phosphatidylcholine) and ethanol at relatively high concentrations with water as non solvent. Ethanol interacts with lipid molecules in the polar head group region, resulting in a reduction in the phase transition temperature ( $\mathrm{Tm}$ ) of the stratum corneum lipids, increasing their fluidity ${ }^{16-21}$. The intercalation of ethanol into the polar head group environment results in an increase in the membrane permeability. In addition to the effects of ethanol on stratum corneum structure, the ethosome itself interacts with the stratum corneum barrier. Ethanol also provides the vesicles softness and flexibility ${ }^{22-25}$. Ethosomes are phospholipid-based elastic vesicles containing $20-45 \%$ ethanol and water. For the preparation of elastic vesicles; ethanol is a proven permeation enhancer that has been added in the vesicular systems. High flexibility imparted by ethanol of vesicular membranes permits the elastic vesicles to squeeze themselves through the pores $^{26-34}$. The proposed mechanism of penetration enhancement with the ethosomal system suggests the intercalation of ethanol into the polar head group environment resulting in increased membrane permeability. With respect to stability, Ethosomes have been reported to be more stable than liposomes because of the presence of ethanol, which provides a net negative charge on the surface, which helps to avoid aggregation of vesicles due to electrostatic repulsion ${ }^{35-42}$. Topically applied ethosomes can increase the residence time of active ingredients in the stratum corneum, epidermis and reduce the systemic absorption of drugs. These properties allow Ethosomes to permeate easily into the deeper layers of the $\operatorname{skin}^{43-48}$. Ethanol is an established efficient permeation enhancer and is present in quite high concentration (20-50\%) in ethosomes. However, due to the interdigitation effect of ethanol on lipid bilayers, it was commonly believed that vesicles could not coexist with high concentration of ethanol ${ }^{49-54}$. Touitou discovered and investigated lipid vesicular systems embodying ethanol in relatively high concentration and named them ethosomes. The basic difference between liposomes and ethosomes lies in their composition. The synergistic effect of combination of relatively high concentration of ethanol 
(20-50\%) in vesicular form in ethosomes was suggested to be the main reason for their better skin permeation ability ${ }^{55-58}$. The high concentration of ethanol (20-50\%) in ethosomal formulation could disturb theskin lipid bilayer organization. Therefore, when integrated into a vesicle membrane, it could give an ability to the vesicles to penetrate the SC. Furthermore, due to high ethanol concentration the ethosomal lipid membrane was packed less tightly than conventional vesicles but possessed equivalent stability. This allowed a softer and malleable structure giving more freedom and stability to its membrane, which could squeeze through small openings created in the disturbed SC lipids. In addition, the vesicular nature of ethosomal formulations could be modified by varying the ratio of components and chemical structure of the phospholipids. The versatility of ethosomes for systemic delivery is evident from the reports of enhanced delivery of quite a few drugs like acyclovir, minoxidil, triphexyphenidyl, testosterone, cannabidol and zidovudine $e^{59-62}$.

\section{MATERIALS AND METHODS}

\section{Acquisition of samples}

\section{Authentification of Calendula officinalis Linn}

Authenticated samples were purchased from the local herb dealer and were again authenticated by the Department of Botany, Yashvantrao Chavan College of Science, Karad.

\section{Preparation of extracts}

Extraction of Calendula officinalis Linn was done by continuous hot extraction method by $95 \%$ $\mathrm{v} / \mathrm{v}$ ethyl alcohol and $85 \% \mathrm{v} / \mathrm{v}$ ethyl alcohol at a temperature of $60{ }^{\circ} \mathrm{C}$ until complete exhaustion of the drug.

\section{Preparation of Ethosomes}

Ethosome colloidal suspensions was made up of 1-3\% (w/v) soya phosphatidylcholine, 30-50\% (v/v) ethanol, Calendula officinalis extract, ethosomes was prepared on trial and error batches. Hot method of preparation is used for ethosome formulation. 


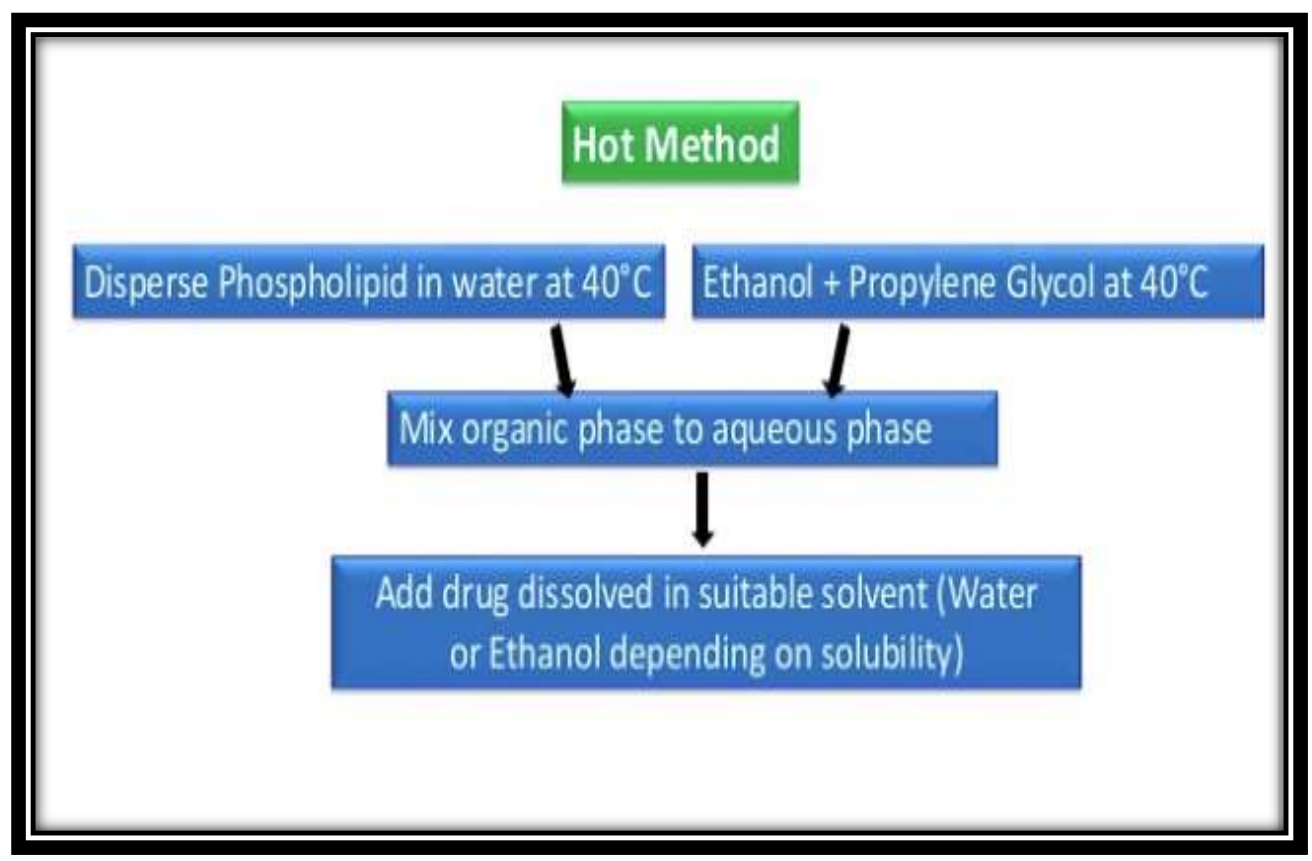

Figure 1. Preparation of Ethosomes

\section{Characterization of Ethosomes}

Morphological characterization of optimized vesicle was done by using a digital microscope with camera at 40x resolution.

\section{Entrapment efficiency}

Vesicle size, size distribution and zeta potential analysis-Zeta potential was a measure of colloidal property of ethosome which affects the permeation and stability of vesicles.

\section{Preparation of cream}

The phase inversion technique was used to prepare the cream base Briefly, lipid phase (olive oil, cetyl alcohol, stearic acid, sorbitanmonooleate, propylene glycol and glycerin) and aqueous phase (Tween 80 and water) was separately heated to $75^{\circ} \mathrm{C}$ and then the hot water phase was added to the lipid phase under constant stirring at $600 \mathrm{rpm}$ depending on trial and error batches. After complete melting and homogenous mixing, temperature was decreased to $30^{\circ} \mathrm{C}$ and ethosome suspension was added at an increased speed $(275 \pm 25 \mathrm{rpm})$. Few drops of rose oil wasadded during stirring to give good odor to the formulation. The base was prepared by the same method as used in the formulation. 


\section{Physicochemical evaluation of cream}

\section{Evaluations of the creams}

Organoleptic properties, pH, homogeneity, viscosity, and rheology were evaluated.

\section{In vitro penetration tests}

Skin penetration tests were conducted using Franz diffusion cells with membrane areas of 2.01 $\mathrm{cm}^{2}$ and a receptor compartment containing $15 \mathrm{~mL}$ of phosphate buffer at $\mathrm{pH} 5.5$. The liquid compartment was maintained at $37^{\circ} \mathrm{C} \pm 0.5^{\circ} \mathrm{C}$ and was stirred with a magnetic stirrer at $250 \mathrm{rpm}$. The skin specimens were placed between the donor and receptor compartments with the stratum corneum facing upward. Subsequently, $1.0 \mathrm{~g}$ samples of the creams were applied to the skin surfaces, and up to $2.0 \mathrm{~mL}$ samples were taken from the receptor compartment using a syringe after 10, 30, 60, 120, 240, 360, 480, 600, 720, 840, 960, 1080, 1200, 1320, and $1440 \mathrm{~min}$. The EGCG concentrations were then determined in these samples using HPLC. In vitro penetration tests were performed 3 times.

\section{RESULTS AND DISCUSSION}

\section{Extraction and Yields}

Table 1. Solvents, extraction methods and respective yield

\begin{tabular}{|c|l|l|l|l|}
\hline Sr. no. & Extract & Solvents & Colour & \% yield w/w \\
\hline 1. & Soxhlet extraction & Ethanol & green & $10.35 \pm 0.87$ \\
\hline
\end{tabular}

\section{Characterization of cream}

\section{Microscopy}

Optical microscopy was done with a digital microscope with camera in 40x resolution.

\section{Qualitative chemical investigation}


The results of qualitative chemical investigation of Calendula officinalis indicated the presence of mainly sterols, terpenoids, flavonoids, phenolic compounds and tannins etc.

Table 2. Qualitative chemical investigation of Calendula officinalis

\begin{tabular}{|c|c|}
\hline Chemical Constituents & $\begin{array}{c}\text { Calendula } \\
\text { officinalis }\end{array}$ \\
\hline Alkaloid (Dragendroff Test) & ++ \\
\hline Glycosides (Borntragers Test) & + \\
\hline Flavonoid (Shinoda Test) & + \\
\hline Steroid (Salkovaski Test) & + \\
\hline Saponins (Foam Test) & + \\
\hline Carbohydrates (Molisch Test) & - \\
\hline \multicolumn{2}{|c|}{++ present - Absent } \\
\hline
\end{tabular}

\section{Preparation of Ethosomes}

Ethosome colloidal suspensions was made up of 1-3\% (w/v) soya phosphatidylcholine, 30-50\% (v/v) ethanol, Calendula officinalis extract, ethosomes was prepared. Hot method of preparation is used for ethosome formulation. The phase inversion technique was used to prepare the cream base Briefly, lipid phase (olive oil, cetyl alcohol, stearic acid, sorbitanmonooleate, propylene glycol and glycerin) and aqueous phase (Tween 80 and water) was separately heated to $75{ }^{\circ} \mathrm{C}$ and then the hot water phase was added to the lipid phase under constant stirring at $600 \mathrm{rpm}$ depending on trial and error batches. After complete melting and homogenous mixing, temperature was decreased to $30{ }^{\circ} \mathrm{C}$ and ethosome suspension was added at an increased speed $(275 \pm 25 \mathrm{rpm})$. Few drops of rose oil was added during stirring to give good odor to the formulation. The base was prepared by the same method as used in the formulation.

\section{Vesicular Size and Shape Analysis}

Developed ethosomes were evaluated for size and shape by using optical microscopy method. Developed ethosomal vesicles were soft and spherical in shape. 


\section{Drug Encapsulation Efficiency}

The percentage drug leakage from developed ethosomes were very less $(<6 \%)$ at refrigerated condition for the entire duration of the study.

\section{Evaluation of cream}

Organoleptic tests showed pale yellow color.. The creams were homogeneous when applied and had $\mathrm{pH}$ values of 5.40 and 5.45, respectively, indicating compatibility with the physiological $\mathrm{pH}$ of skin and the stability. The viscosity values of the creams were 11,800 and 11,200 cps, respectively, and both creams had thixotropic plastic rheology properties.

\section{In vitro penetration tests}

After applying the topical preparations, the cumulative amounts of EGCG that penetrated the Franz diffusion cells were $2442.57 \pm 93.47 \mu \mathrm{g} / \mathrm{cm}^{2}$ for ES, $3897.67 \pm 1380.29 \mu \mathrm{g} / \mathrm{cm}^{2}$ for ethosome suspensions (ET), $413.92 \pm 52.83 \mu \mathrm{g} / \mathrm{cm}^{2}$ for CE, and $905.75 \pm 49.47 \mu \mathrm{g} / \mathrm{cm}^{2}$ for CET. We also calculated the flux of the active substance (EGCG) through rat skin and expressed these data as circulating EGCG per unit area per unit time. The flux values for ES, ETS, CE, and CET were 109.032 $\pm 21.969,131.65 \pm 66.03,12.66 \pm 1.45$, and 40.96 $\pm 5.56 \mu \mathrm{g} . \mathrm{cm}-2 / \mathrm{h}$, respectively. Based on these results, we suggest that CET achieves better penetration than CE. In addition, the ethosomal suspension had better penetration than the ES, indicating that ethosomes in topical creams can improve EGCG penetration through rat skin. The present ethosomal suspensions have a high ethanol content, which enhances penetration through hydrogen bond interactions with the phospholipid layers of the stratum corneum. Ethanol also facilitates the passage of the active ingredient into deeper skin layers by enhancing flexibility of following fusion of the ethosome vesicles with lipids in skin membranes

\section{CONCLUSION}

Ethosomes elicit potential to deposit Calendula officinalis Linn into the deeper layers of skin in order to exert its antioxidant effect. Calendula officinalis linn entrapment was significantly improve with ethanol extract (\% of ethanol on batches was determined on trial and error batches). It improved in overall elasticity, biological elasticity, recovery of deformed skin, firmness and reduction in fatigue which can be correlated with anti wrinkle properties of cream. 
These beneficial effects might have been due to the synergistic antioxidant, anti-inflammatory and protective properties of the constituents of extract and hydrant, moisturizing and lipid components of ethosomes and cream. Therefore, it may be conclude that proposed cream is multipurpose use as anti-wrinkle cream, Sun screen cream, protective skin irritation cream, Wound healing cream which was more effective.

\section{ACKNOWLEDGMENTS}

The author have especially thankfully to the Dr. A.R. Dhole Assistant professor of Quality Assurance Rajarambapu college of pharmacy, Kasegoan for guidance and encouraging in the research work.

\section{REFERENCES}

1. Touitou E, Dayan N, Bergelson L, Godlin B, Eliaze M. Ethosome-novel vasicular carrier for enhanced delivery: characterization and skin penetration properties. J. Control Release. 2000; 65: 403-418.

2. Akhtar N, Zaman SU, Khan BA, Amir MN.Calendula Extract: Effect on mechanical parameters of human skin. Acta Poloniae Pharamaceutica. 2001; 68: 693-701.

3. Ajazuddin, Saraf S. Evaluation of physicochemical and phytochemical properties of SafoofE-Sana, a Unani polyherbal formulation. Pharmacognosy Res. 2010; 2: 318-322.

4. Benson HAE. Transdermal Drug Delivery: Penetration Enhancement Techniques. Current. Drug. Delivery. 2010;2: 23-33.

5. Yadav A, Mohite S. Aquasomes as a Self Assembling Nanobiopharmaceutical Carrier System for Bio-Active Molecules. Research J. Topical and Cosmetic Sci. 2020; 11(2): 66-70.

6. Kirjavainen M, Urtti A, Jaaskelainen I, et al. Interaction of liposomes with human skin in vitro-the influence of lipid composition and structure. Biochim Biophys Acta. 1996;1304:179Y189.

7. Paolino D, Lucania G, Mardente D, Alhaique F, Fresta M. Ethosomes for skin delivery of ammonium glycyrrhizinate: in vitro percutaneous permeation through human skin and invivo anti-inflammatory activity on human volunteers. J Control Release. 2005; 106:99Y110.

8. Lopez-Pinto JM, Gonzalez-RodriguezML, Rabasco AM. Effect of cholesterol and ethanol on dermal delivery from DPPC liposomes. Int J Pharm. 2005; 298:1Y12. 
9. Yadav A, Mohite S. Potential Role of Peptides for Development of Cosmeceutical skin Product. Research J. Topical and Cosmetic Sci. 2020; 11(2): 77-82.

10. Yadav A, Mohite S. Applications of Nanotechnology in Cosmeceuticals. Research J. Topical and Cosmetic Sci. 2020; 11(2): 83-88.

11. Holimon TD, Chafin CC, Self TH. Nocturnal asthma uncontrolled by inhaled corticosteroids: theophylline or long-acting beta2 agonists? Drugs. 2001;61:391Y418.

12. Yadav A, Mohite S. Recent advances in protein and peptide drug delivery. Res. J. Pharma. Dosage Forms and Tech. 2020; 12(3): 205-212.

13. Pilgram GS. Electron diffraction provides new informa-tion of human stratum corneum lipid organization studied in relation to depth and temperature. J Invest Derm 1999; 113: 403409.

14. Schreier H, Bouwstra JA. Liposomes and niosomes as topical drug carriers: dermal and transdermal drug delivery. J Control Rel 1994; 30: 1- 15.

15. Gangwar Satyam, Singh Shivani, Garg Garima. Etho-somes: A novel tool for drug delivery through the skin. J Pharm Res 2010; 3(4): 688-691.

16. Touitou E., Godin B., Dayan N., Piliponsky A., Levi-Schaffer F., Weiss C., Intracellular delivery mediated by an ethosomal carrier, Biomaterials, 2001; ,22, 3053-3059

17. Yadav A, Mohite S. Potential Role of Peptides for Development of Cosmeceutical skin Product. Research J. Topical and Cosmetic Sci. 2020; 11(2): 77-82.

18. Verma DD, Fahr A. Synergistic penetration effect of ethanol and phospholipids on the topical delivery of Cyclosporin A. J Control Rel 2004; 97: 55-66.

19. Yadav A, Mohite S. Applications of Nanotechnology in Cosmeceuticals. Research J. Topical and Cosmetic Sci. 2020; 11(2): 83-88.

20. Touitou E, inventor. Composition of applying active substance to or through the skin. US patent 5540 934, July 30, 1996.

21. Yadav A, Mohite S. Recent advances in protein and peptide drug delivery. Res. J. Pharma. Dosage Forms and Tech. 2020; 12(3): 205-212.16. Mali H, Shaikh S, Yadav A. Development of Solid Self-Emulsifying Formulation for Improving the Oral Bioavailability of Artemether. International Journal Of Creative Research Thoughts 2021; 9(6): c257- c273.

22. Salunkhe K, Yadav A. Recent Advances in Manufacturing Technologies and Future Prospects of Mouth Dissolving Tablets (FDTs). Int J Sci Res Chemi. 2020; 5(2): 26-32. 
23. Suryawanshi V, Yadav A, Birajdar R. Optimization of Ayurvedic Herbal Medicine by Nanoformulation. Asian Journal of Research in Pharmaceutical Sciences. 2019; 9(1): 55-56.

24. Yadav A, Mohite S. Formulation and Evaluation of Antidandruff Shampoo. Research J. Topical and Cosmetic Sci.2020; 11(2): 55-58.

25. Yadav A. Preparation and Evaluation of Herbal Mouthwash containing Psidium guajava Leaf Extract. International Journal of Pharmaceutical Research and Development. 2020; $2(1): 24-26$.

26. Birajdar R, Yadav A, Patil S, Chitruk A, Kane S, Mohite S, Magdum C. Pharmacognostic and Phytochemical Investigation, Molecular Docking Studies of Phytoconstituents and Anticancer Potential of Capparis Decidua (Forsk) Edgew. Journal of University of Shanghai for Science and Technology. 2020; 22(11): 500-519.

27. Yadav A, Raut I, Vakhariya R. Formulation \& Evaluation of Herbal Lipstick using Morus alba Linn. International Journal of Pharmacy and Pharmaceutical Science. 2020; 2(1): 0405 .

28. Patil S, Yadav A, Chopade A, Mohite S. Design, Development and Evaluation of Herbal Mouthwash for Antibacterial Potency against Oral Bacteria. Journal of University of Shanghai for Science and Technology. 2020; 22(11): 881-898.1137-1148.

29. Yadav A, Mohite S. Anthelmintic and Antibacterial Activity of Psidium Guajava Leaf Extracts. Int J Sci Res Chemi. 2020; 5(6): 06-11.

30. Yadav A, Mohite S. Rajput M, Suryawanshi V, Birajdar R, Patil M. Antioxidant Activity of Psidiumguajava Leaf Extracts. Res. J. Pharma. Dosage Forms and Tech. 2020; 12(3): 159161.

31. Honmane P, Mali V, Mali A, Mahadik P, Yadav A, Mohite S. Formulation and Evaluation of Herbal Ointment Containing Eclipta Alba (L.) Extract. Journal of Seybold Report. 2020; 25(10): 569-577.

32. Yadav A, Honmane P, Bhosale M, Chitruk A, Rode P, Birajdar R, Rajput M, Suryawanshi V, Patil S, Patil, Jagtap N, Mohite S, Dange V, Vambhurkar G. Antifungal Activity of Malvastrum Coromandelianum Leaf Extracts.Int J Sci Res Chemi. 2020; 5(6): 01-05.

33. Dange V, Dinde S, Doiphode A, Dhavane S, Dudhal B, Shid S, Yadav A. Formulation and Evaluation of Herbal gel Containing Lantana Camara for Management of Acne Vulgaris. Journal of University of Shanghai for Science and Technology. 2020; 22(11): 799-809. 
34. Yadav A, Mohite S. Screening of In-vitro anti-inflammatory and Antifungal assay of Psidium guajava Leaf Extracts. Research J. Topical and Cosmetic Sci. 2020; 11(2): 62-64.

35. Yadav A, Gavali K, Rajput M, Pathade K, Patil S, Dharanguttikar V, Mohite S. Anthelmintic Activity of Malvastrum Coromandelianum Leaf Extracts against Pheretima Posthuma and Ascardia Galli. Int J Sci Res Chemi. 2020; 5(6): 18-24.

36. Suryawanshi V, Yadav A, Mohite S. Toxicological Assessment using Brine Shrimp Lethality Assay and Antimicrobial activity of Capparis Grandis. Journal of University of Shanghai for Science and Technology. 2020; 22(11): 746-759.

37. Yadav A, Rajput M, Gavali K, Pathade K, Honmane P, Mohite S. Anthelmintic and Antibacterial Activity of PsidiumGuajava Leaf Extracts. Int J Sci Res Chemi. 2020; 5(6): 611.

38. Yadav A, Mohite S. Toxicological Evaluation of Eclipta alba using Brine Shrimp (Artemia salina L.) Model. Int J Sci Res Chemi. 2020; 5(6): 56-62.

39. Pawara N, Yadav A, Mohite S. Pharmacognostic, Phytochemical Investigation and Antioxidant Potential of Embelia ribes. Int J Sci Res Chemi. 5(6): 27-34.

40. Yadav A, Mohite S. In vitro Studies on the Inhibition of $\alpha$-amylase and $\alpha$-glucosidase by Methanolic Extract of Barleria Prionitis L. and Psidium guajava. Int J Sci Res Chemi. 2020; 5(1): 50-58.

41. Yadav A, Honamane P, Rajput M, Dange V, Salunkhe K, Kane S, Mohite S. Antimalarial Activity of Psidium guajava Leaf Extracts. Int J Sci Res Chemi. 2020; 5(6): 63-68.

42. Gavali K, Yadav A, Howal R, Tamboli A. Preliminary Phytochemical Screening and HPTLC Finger printing of Leaf Extracts of Tectona grandis Linn Journal of University of Shanghai for Science and Technology. 2020; 22(11): 1804-1815.

43. Yadav A, Mohite S. Anticancer Activity and In-Silico ADMET Analysis of Malvastrum Coromandelianum. International Journal of Pharma Sciences and Research. 2020; 11(5): $71-73$.

44. Yadav A, Mohite S. Toxicological Evaluation of Psidium guajava Leaf Extracts using Brine Shrimp (Artemi salina L.) Model. Res. J. Pharma. Dosage Forms and Tech. 2020; 12(4): 198-120. 
45. Cevc G (1996) Transfersome, liposomes and other lipid suspensions on the skin: permeation enhancement, vesicle penetration, and transdermal drug delivery. Crit. Rev. Therap. Drug. Carrier Syst. 13: 257-238.

46. Gunjan J (2014) Topical Delivery of Curcuma longa Extract Loaded Nanosized Ethosomes to Combat Facial Wrinkles. Research Article Journal of Pharmaceutics \& Drug Delivery Research. 3:1.

47. Yadav A, Rajput M, Gavali K, Mohite S. In-vitro Hypoglycemic Activity of Barleria prionitis L. Int J Sci Res Chemi. 2020; 5(5): 63-70.

48. Yadav A, Mohite S. Screening of In-vitro anti-inflammatory and Antibacterial assay of Malvastrum Coromandelianum. International Journal of Pharma Sciences and Research. 2020; 11(4): 68-70.

49. Vaibhav Dubey, Dinesh Mishra, JainN.K. Melatonin loaded ethanolic liposomes Physiochemical characterizationand enhanced transdermaldelivery. Eur J Pharm and Biopharm 2007; 67: 398-405.

50. Yadav A, Mohite S. ADME analysis of phytochemical constituents of Psidium guajava. Asian J. Res. Chem. 2020; 13(5): 373-375.

51. Yadav A, Mohite S. LC 50 Determination of BarleriaPrionitis L. by Brine Shrimp Lethality Assay. Int J Sci Res Chemi. 2020; 5(2): 26-32.

52. Kundlik Girhepunj, Ranju Pal, Hitesh Gevariya, Atanu-kumar Behera, Thirumoorthy N. Ethosomes: A Novel Vesicular Carrier for Enhanced Dermal Delivery of Cic-lopiro xOlamine. DerPharm Let 2010; 2(1): 360-367.

53. Ehab R. Bendas, Mina I Tadros.Enhanced transdermal delivery of salbutamol sulphate via ethosomes. AAPS Pharm.Sci.Tech 2007; 8(4):E1_E8.

54. Yadav A, Mohite S. Anticancer Activity of Psidium guajava Leaf Extracts on Breast Cancer Cell Line. Res. J. Pharma. Dosage Forms and Tech. 2020; 12(4): 298-300.

55. Yadav A. In-vitro Studies on the Inhibition of $\alpha$-amylase and $\alpha$-glucosidase by Methanolic Extract of Lawsonia inermis and Malvastrum coromandelianum. International Journal of Pharmacognosy and Pharmaceutical Research. 2020; 2(1): 09-12.

56. Yadav A, Mohite S. Anticancer Activity of Psidium guajava Leaf Extracts on Breast Cancer Cell Line. Res. J. Pharma. Dosage Forms and Tech. 2020; 12(4): 298-300. 
57. Yadav A. In-vitro Studies on the Inhibition of $\alpha$-amylase and $\alpha$-glucosidase by Methanolic Extract of Lawsonia inermi sand Malvastrum coromandelianum. International Journal of Pharmacognosy and Pharmaceutical Research. 2020; 2(1): 09-12.

58. Kundlik Girhepunj, Ranju Pal, Hitesh Gevariya, Atanu-kumar Behera, Thirumoorthy N. Ethosomes: A Novel Vesicular Carrier for Enhanced Dermal Delivery of CiclopiroxOlamine. Der Pharm Let 2010; 2(1): 360-367.

59. Yadav A. Assessment of Bioactivity of Lawsoniai nermis Linn.using Brine Shrimp (Artemia salina) Lethality Assay. International Journal of Pharmacognosy and Pharmaceutical Research. 2020; 2(1): 13-16.

60. Ehab R. Bendas, Mina I Tadros. Enhanced transdermal delivery ofsalbutamol sulphate via ethosomes.AAPS Pharm.Sci.Tech 2007; 8(4):E1_E8.

61. Yadav A. In-vitro Hypoglycemic Activity of Lawsonia inermis Linn. Leaf Extracts. International Journal of Pharmacognosy and Pharmaceutical Sciences. 2021; 3(1): 01-04.

62. New RRC. Preparation of liposomes andsize determi-nation, In: Liposomes APractical Approach. New RRC (Ed.),Oxford University Press, Oxford, 1990;36-39.

63. Biana Godin, Elka Tauitou. Erythromycin Ethosomal Systems: Physiochemical Characterization and En-hanced Antibacterial Activity. Curr Drug Deliv2005; 2: 269-275. 